\title{
Development of Soil Environmental Management Information System: A Case Study in Shandong Province
}

\author{
Guanglu $\mathrm{Hu}^{1}$, Jiemin Cheng ${ }^{2}$, Mingcong Wang ${ }^{2}$ \\ ${ }^{1 .}$ School of Information Engineering, Shandong Youth University of Political Science, 250014 Jinan China \\ 2. College of Population Resources \& Environmental Science, Shandong Normal University Jinan, 250014 China
}

\begin{abstract}
A soil heavy metals information system in Shandong province was constructed based on environment quality assessment modeling technologies for heavy metals contaminated soils. The system integrates the VB.net software, GIS software MapInfo\MapX and DBMS SQL Server2000. The system includes four main modules: (1) soil type and heavy metals content information management, query and updating, (2) soil heavy metals environment quality assessment (3) the critical value of soil heavy metal pollution and (4) the soil heavy metals environment quality warning. The sampling usage of the system demonstrates that it is of great significance to regional soil heavy metals information management, sharing and decision-making supporting.
\end{abstract}

Keywords-soil; heavy metals; geographic information; database.

\section{INTRODUCTION}

Soil information is often used as part of spatial decisionmaking processes[1]. However, it is necessary to have information harmonized both in space and time[2]. With the rapid development of computer technology and GIS (geographic information system), a paper map can be vectoring converted into an electronic map. To implement topographic map digitalization by means of MAPGIS is one of main means of getting spatial geographic information data[3]. The integration of EMS (Environment Management System) and GIS can realize the combination of environment attribute data and spatial geographical information data and enable GIS to share the environment information data in EMS system[4] Entering and extracting of information once it is compiled into the GIS become much easier, more efficient and faster[5].
The aim of this paper is to describe how to create a Soil Heavy Metals Information System, and to identify areas with the problems of soil environment quality due to pollution. A soil heavy metals information system in Shandong province was constructed based on environment quality assessment modeling technologies for heavy metals contaminated soils. The system integrates the software VB.net, GIS software MapInfolMapX, and DBMS SQL Server2000. The information system introduced here will assist the planning and decision making processes which is a great importance for Shandong province.

\section{DESIGN OF SOIL HEAVy Metals Information SYSTEM}

\section{A. System architecture.}

Based on the analysis of system requirements, the Soil Heavy Metals Information System is divided into three logic levels parts, which are in the order of information presentation layer, system function layer and operating system support layer (Figure1). Information presentation layer is mainly to complete the user's request and output and display the results. System function layer is mainly to complete the system application function, and it is the kernel of the whole system. Operating system support layer supports system running environment, such as computer networks, communication facilities, database, model base, method base, knowledge base GIS etc. The system can effectively reduce the work load, improve database response speed, and it is convenient for management and maintenance of the system. 


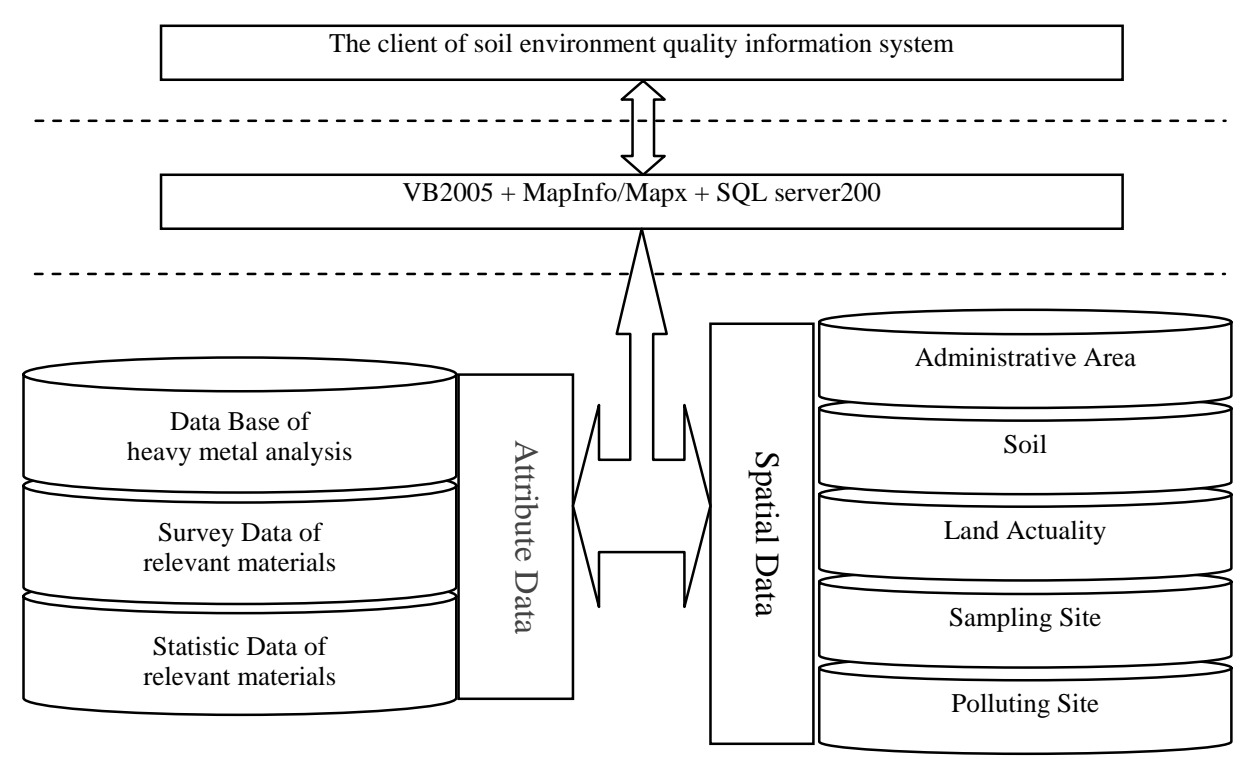

Figure 1. System architecture design

\section{B. System function}

Fig.2. shows the system function module design based on consulting literature and market research. From figure we knows:

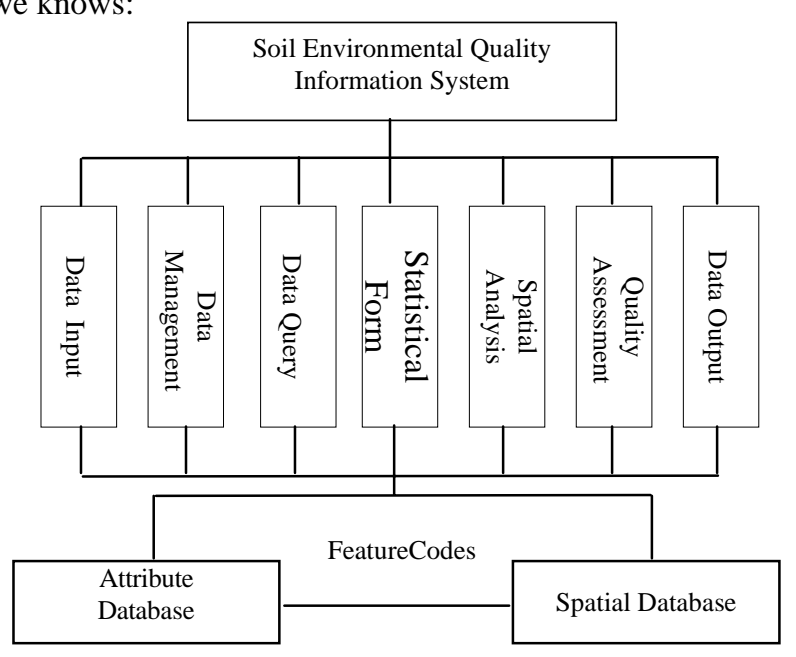

Figure 2. Function module

i) Data management: Implementation of station information under authorization, soil monitoring data entry, checking and updating.

ii) Soil environmental quality assessment: the function based on the Standard of Soil Environment (Chinese National Standard GB15618-1995) and the method of soil environment pollution and implementation of automatically writing the assessment result to the database.

iii) Soil environmental quality data statistics analysis: implementation of soil environmental quality data statistics analysis such as mean, min, and max of pollution index and heavy metals content, exceeding multiple and exceeding ratio of pollutants based on single-item and synthesis pollution criterion index and implementation of the dynamic update of statistics

iv) Soil environmental quality data query: query monitoring points or areas and soil environmental quality monitoring information query.

v) Soil environmental quality in spatial analysis: to create a table, histogram or pie chart that visually demonstrates the parameters of soil environmental quality in a certain period.

vi) Graphical data manipulation:

a. Basic graphics operation function. The system has the function of GIS spatial graphical data manipulation, such as the graph zooming, the full-size graphic display, the graphic pull box zooming, the map random, the spatial distance measuring, the multiple shapes selecting and eagle eye.

b. Thematic graphs and printout. To generate the corresponding thematic graphs according to a query requirement and to print out with variety printout formats.

\section{System data processing}

Information system data process includes space data acquisition, database establishment and management, data output etc. Accord to user requirement analysis (URA), the SQL Server2000 database named "Environment" consists of 15 tables, such as a user table, analysts table, comprehensive quality classification table, soil type table, soil standard table, land use patterns etc. The basic geographic data from the SEQIS, such as soil type map, layout diagram of soil monitoring sites, administrative division map, land use classification map, are digitized in the MapInfo and stored in the form of documents. The basic geographic data formed the data format identified by the MapX component and spatial data and attribute data are stored separately, namely, dual database storage mode of the MapInfo. The attribute data are stored in several attribute tables of relational database and the spatial data in a custom the MapInfo format are stored in several files. The 
spatial data are linked to the attribute data though a certain index mechanism. The efficiency of query and processing are improved greatly by the spatial data of hierarchical structure in the MapInfo. The flow chart of data processing is shown in fig.3.

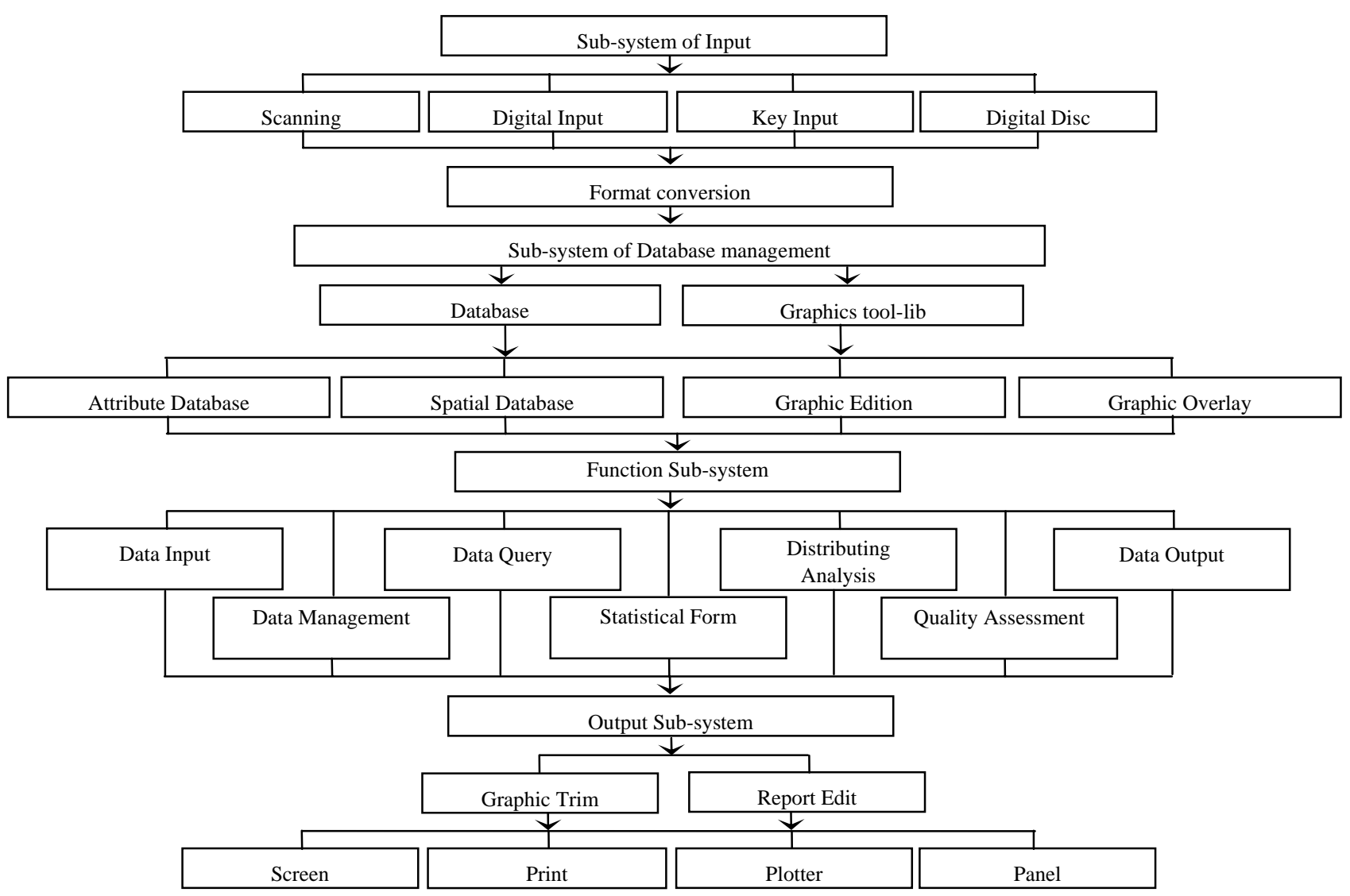

Figure 3. Block diagram of system data

\section{A CASE OF IMPLEMENTATION AND OPERATION OF SYSTEM FUNCTION}

In this paper, the operation interface of the Soil Heavy Metals Information System is introduced with a real example used in a county in Shandong Province.

\section{A. Comprehensive environmental quality evaluation form}

With the administrative region, soil types, vegetation types, etc., as input, the results of the comprehensive environmental quality evaluation could be acquired in the comprehensive environmental quality evaluation form, as shown in figure 4 (translated from Chinese).

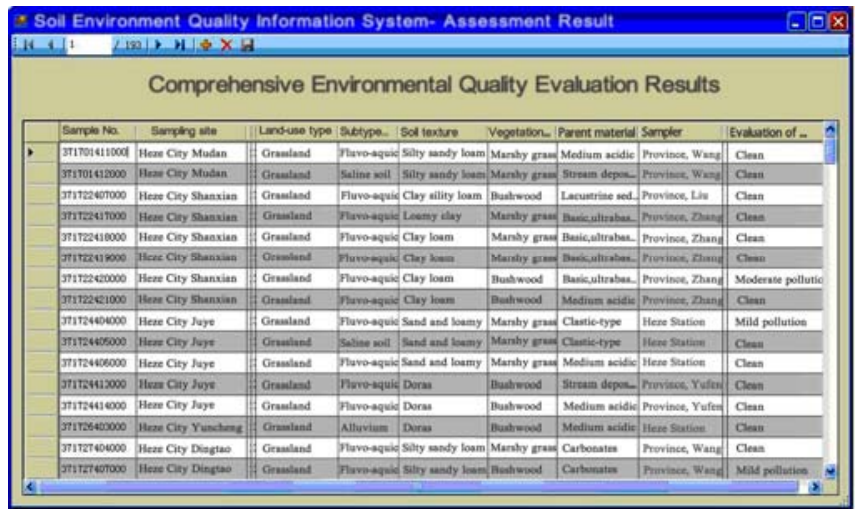

Figure 4. Comprehensive evaluation results window

\section{B. Soil environmental quality evaluation with a sampling county as a unit}

The results of soil environmental quality evaluation were gained with the VB2005 and the Office Chart Tool.

i) The comprehensive environmental quality evaluation pie 
When a county selected, the comprehensive environment quality results of each sampling point from a county in Shandong Province can be intuitively seen in figure 5 .

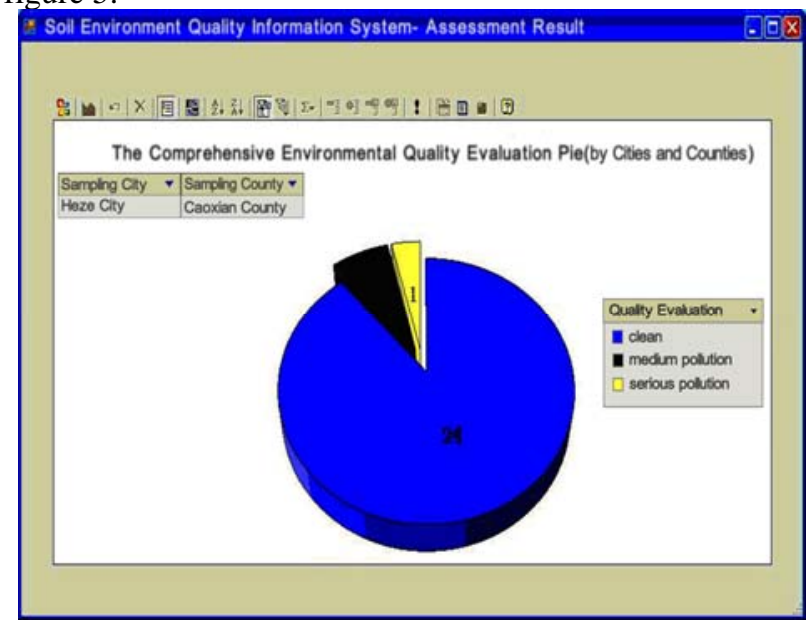

Figure 5. Soil environmental quality evaluation window

ii) Statistical results of heavy metals in soil in the county

When a county selected, the means of different heavy metals total contents and available contents in soil can be intuitively seen in figure 6 .

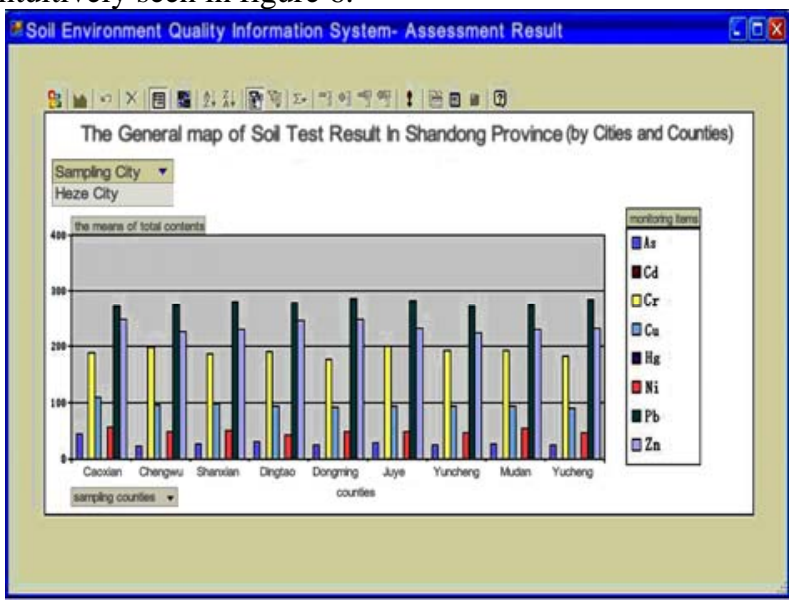

Figure 6. Statistical results of heavy metals in soil in a county window

iii) Statistical results of analysis of monitoring in soil type

When a soil type selected in the province or the county, the means of different heavy metals total contents and available contents in different soil type can be intuitively seen in figure 7.

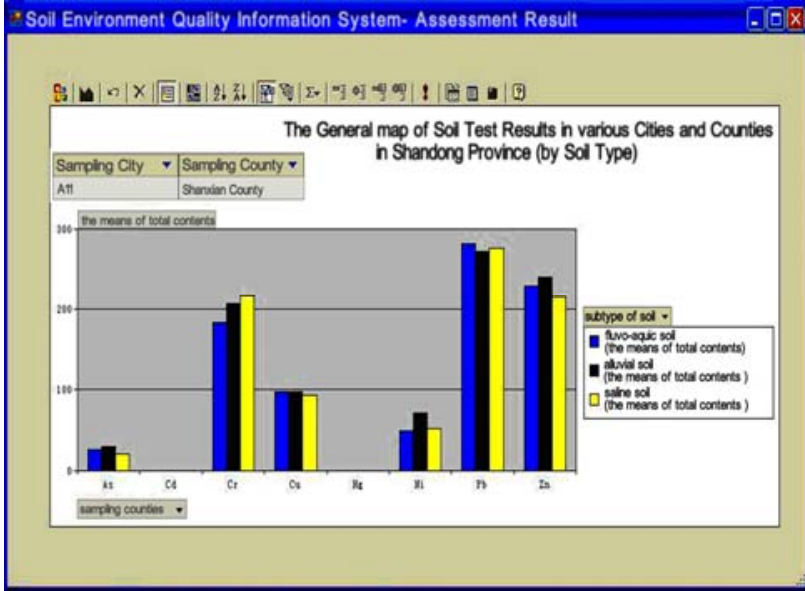

Figure 7. Statistical results of heavy metals in soil type window

\section{CONCLUSION}

The Soil Heavy Metals Information System studied in this paper was based on the CIS technology. The combination of the geographical spatial data and attribute data, provided a comprehensive, intuitive, rapid visualization query and specific information retrieval and carried on statistics and evaluation. The study result will provide technical support for the decision making of land resources and soil environmental management, as well as useful information for reference of scientific, standardized management for soil environment quality forecast and warning work.

\section{ACKNOWLEDGEMENTS}

The authors would like to thank the National Natural Science Fund Committee, China (41171251) and the Ph.D. Programs Foundation of Ministry of Education of China (20103704110001) for financial support.

\section{REFERENCES}

[1] Zhang Ganlin, Gong Zitong, Luo Guobao,(2001) The Structure, Content and Applications of State Soil Information System [J]. Scientia Geographica Sinica21(5):401-405

[2] Bouma, J. and Bregt, A.K.:(1989)Land qualities in space and time. Proceedings of a symposium organized by the International Society of Soil Science (ISSS), Wageningen, the Netherlands , 22-26

[3] YAO Ling, ZHANG Li-ping, ZHANG Shu-jie, ZHOU Zeng-po:(2011) Design and Implementation of Soil Environmental Quality Database Soils , 43 (5): 842-849

[4] JIA Xiaohong, GAO Rutai, DUAN Zengqiang, HUANG Yuanfang, CHEN Qing: (2007) Construction of a soil resource management and fertilization decision-making information system at county scale: A case study in Pinggu, Beijing, Ecology and Environment, (2007) 16(5): 1521-1527

[5] Finke, P., R. Hartwich, R. Dudal, J. Ibanez, M. Jamagne, D. King, L. (2003)Montanarella and N. Yassoglou Manuel of Procedures. Georefenced Soil Database for Europe. European Commission Joint $\begin{array}{llll}\text { Resarch } & \text { Centre. } & \text { Italy. } & \text { p }\end{array}$ 